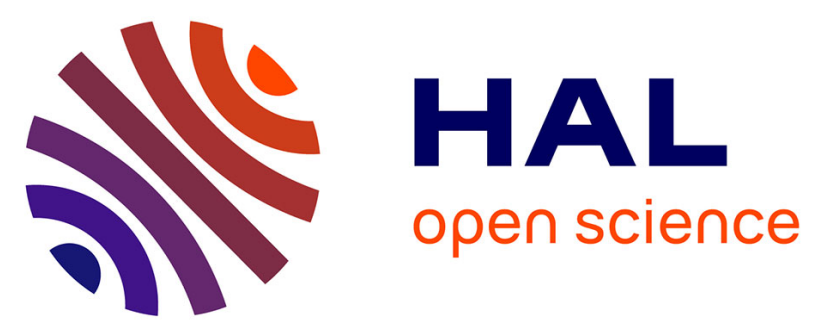

\title{
Abnormal C-reactive protein blood levels as a specific biomarker of major depression and non-remission under antidepressants in schizophrenia
}

\author{
Guillaume Fond, J.A. Micoulaud-Franchi, M. Faugere, L. Boyer, C.
} Faget-Agius, C. Lançon, R. Richieri, M. Cermolacce

\section{To cite this version:}

Guillaume Fond, J.A. Micoulaud-Franchi, M. Faugere, L. Boyer, C. Faget-Agius, et al.. Abnormal C-reactive protein blood levels as a specific biomarker of major depression and non-remission under antidepressants in schizophrenia. Progress in Neuro-Psychopharmacology and Biological Psychiatry, 2020, 97, pp.109800. 10.1016/j.pnpbp.2019.109800 . hal-02473229

\section{HAL Id: hal-02473229 \\ https://hal-amu.archives-ouvertes.fr/hal-02473229}

Submitted on 10 Feb 2020

HAL is a multi-disciplinary open access archive for the deposit and dissemination of scientific research documents, whether they are published or not. The documents may come from teaching and research institutions in France or abroad, or from public or private research centers.
L'archive ouverte pluridisciplinaire HAL, est destinée au dépôt et à la diffusion de documents scientifiques de niveau recherche, publiés ou non, émanant des établissements d'enseignement et de recherche français ou étrangers, des laboratoires publics ou privés.

\section{(ㅇ)(1) $\$$}

Distributed under a Creative Commons Attribution - NonCommercial - NoDerivatives| 4.0 


.

Abnormal C-reactive protein blood levels as a specific biomarker of major depression and nonremission under antidepressants in schizophrenia.

$$
\text { Fond } \mathrm{G}^{1,2 *} \text {, Micoulaud-Franchi JA, Faugere } \mathrm{M}^{1,2} \text {, Boyer } \mathrm{L}^{1,2} \text {, Faget-Agius } \mathrm{C}^{1,2} \text {, Lançon } \mathrm{C}^{1,2} \text {, }
$$
Richieri $\mathrm{R}^{1,2,6}$, Cermolacce $\mathrm{M}^{1,2}$,

1Department of Psychiatry, La Conception University Hospital, 13005 Marseille, France.

2 EA 3279 - EA 3279: CEReSS - Health Service Research and Quality of Life Center, 27 Boulevard Jean Moulin,13005 Marseille, France

3 SHU Adult Psychiatry, Sainte Marguerite University Hospital, 13274 Marseille, France.

\section{* Correspondence should be sent to: Dr Guillaume FOND}

AP-HM, Aix-Marseille Univ, Faculté de Médecine - Secteur Timone, EA 3279: CEReSS -Centre d'Etude et de Recherche sur les Services de Santé et la Qualité de vie, 27 Boulevard Jean Moulin, 13005 Marseille, France

Tel: (33 6681022 58), e-mail: guillaume.fond@ap-hm.fr 
Abstract

Background. C-reactive protein (CRP) is a general marker of peripheral inflammation and has been shown to be a good marker of neuroinflammation. CRP has been found to be elevated in patients with mood disorders (especially unipolar disorders (UD) and in schizophrenia (SZ)) but also to be lowered by antidepressants.

Objective: The objectives were (i) to determine the prevalence of major depression, antidepressant prescription and remission under antidepressant in a stabilized population of SZ and UD patients consulting in a daily hospital, and (ii) to determine if CRP was a marker of major depression and remission under antidepressant in these SZ and UD populations.

Methods: Abnormal CRP was defined by a CRP blood level $\geq 3 \mathrm{mg} / \mathrm{L}$. Depressive symptoms were assessed by the Calgary Depression Rating Scale score. The clinicians were blinded of the CRP status of the patient.

Results: 411 patients were included (272 SZ and 139 UD). 171 (41.6\%) were diagnosed with current major depression (74 (27.2\%) for SZ and 97 (69.8\%) for UD). 86 SZ (31.6\%) and 119 UD (85.6\%) were treated by antidepressant. Only 28/74 (37.8\%) of the SZ subjects with major depression were administered antidepressants vs. 87/97 (89.7\%) for UD. The non-remission rate under antidepressant was 28/86(32.6\%) for SZ and 87/119 (73.1\%) for UD. Overall, 105 (40.1\%) of SZ and 39 (28.1\%) of UD patients were found to have abnormal CRP blood levels. Abnormal CRP levels were significantly associated with increased MDD and more strongly with increased rates of non-remission under antidepressants in SZ patients, independently of age, gender, psychotic symptomatology, functioning, tobacco smoking and metabolic syndrome. This result was not replicated in UD patients, which suggests that CRP may be a specific marker of major depression and remission under antidepressant in SZ patients.

Conclusion: The development of biomarkers in psychiatry may orientate specific etiologic therapies in patients with mental disorders. The present findings suggest that major depression is frequent in SZ patients and that increased CRP levels are associated with non-remission under antidepressants in this population. Anti-inflammatory strategies may be particularly useful in this specific population.

Keywords: inflammation; schizophrenia; major depression; antidepressant; biomarker 


\section{Introduction}

Major depression is frequent across severe mental disorders (including schizophrenia (SZ) and unipolar disorders (UD)) and responsible for a high part of poor prognosis, impaired functioning and quality of life in these patients (Guillaume Fond et al., 2018a). In schizophrenia, almost half of the patients have a major depression issue. Among them, one third is correctly diagnosed and treated with antidepressants, one third is diagnosed and treated but unremitted, and one third is non-diagnosed and non-treated (Guillaume Fond et al., 2018a). One explanation may be the difficulty to detect major depression in SZ patients that exhibit more frequently hostility, impaired help seeking and blunted affect. Developing a biomarker of major depression in schizophrenia would therefore be useful to improve its detection and treatment. In the same line, identifying a predictor of antidepressant remission may help clinician to guide personalized interventions in SZ patients with major depression.

Immunopsychiatry has yielded major findings in the last two decades. Among those, each severe mental disorders has been associated with specific immune-inflammatory disturbances (Guillaume Fond et al., 2015). Blood highly-sensitive C-reactive protein (hs-CRP) is the most common biomarker of chronic peripheral inflammation and has been recently shown to be also a good biomarker of central/brain inflammation (Felger et al., 2018). C-reactive protein is produced by the liver in response to the increase of the interleukin-6, an interleukin that has been found to be increased in both SZ and UD (Guillaume Fond et al., 2015).

In a recent systematic review, we have concluded that increased CRP may be considered as a biomarker for SZ onset risk, as well as a risk factor for increased positive symptoms, cognitive impairment in SZ subjects (Guillaume Fond et al., 2018b). CRP has been recently shown to be a biomarker of resistance into antipsychotic treatment in SZ subjects (G. Fond et al., 2018a). CRP may also be particularly increased in patients with metabolic syndrome or tobacco smoking, two major sources of inflammation in SZ subjects (Fond et al., 2017a).

Beyond SZ, increased CRP has been extensively associated with depressive symptoms in general population and mood disorders, and antidepressants have been found to have anti-inflammatory effects (Hannestad et al., 2011). On the contrary, conflicting results were found for the association between CRP and depressive symptoms as well as on the effect of antidepressants in SZ patients (Faugere et al., 2018; Fond et al., 2016). Given that SZ and UD have been associated with different immunological disturbances, these different immune-inflammatory signatures may explain these discrepancies. However, SZ and UD depressive symptoms as well as the response to antidepressants have never been directly compared to determine if CRP was a biomarker of major depression in both SZ and UD patients. Moreover, no study has explored the association between increased CRP and remission under antidepressants. If antidepressants have anti-inflammatory effects, one may hypothesize that increased CRP may be associated with non-remission under antidepressants. 
The objective of the present study was to determine if abnormal hs-CRP blood levels were a biomarker of increased major depression and increased non-remission under antidepressant in respectively SZ and UD patients.

\section{Methods}

\subsection{Study participants}

The patients were consecutively recruited in the daily psychiatric academic hospital from SainteMarguerite hospital, Marseille, France, from October 2010 to May 2015. The inclusion criteria were: (1) age 18-85 years old, (2) diagnosis of SZ or UD according to the DSM-IV-TR criteria, (3) French as native language (4) stabilized with a background treatment (antipsychotic and/or antidepressant) for at least 8 weeks. The exclusion criteria were: (1) chronic somatic illness and specifically inflammatory or central nervous system illness and (2) mental retardation.

\subsection{Ethical statement}

The data collection was approved by the Commission Nationale de l'Informatique et des Libertés (CNIL number 1223715). The study was designed in accordance with the Declaration of Helsinki and French good clinical practice. All of the patients were informed of the study and gave written informed consent.

\subsection{Data Collection.}

The following data were collected:

Chronic peripheral inflammation

Serum highly-sensitive CRP (hs-CRP) levels were determined using sensitive regular immunoassays (ELISA). The results were expressed as milligram per liter. The detection limit was $0.08 \mu \mathrm{g} / \mathrm{ml}$. Patients were classified into two groups: normal CRP level $(\leq 3.0 \mathrm{mg} / \mathrm{l})$ and high CRP $(>3.0$ mg/l)(Wysokiński et al., 2014).

\section{Major depression}

Major depression was evaluated with the Calgary Depression Rating Scale (CDSS) (Addington et al., 1993) that was validated from a long time in SZ but only recently in UD (Micoulaud-Franchi et al., 2018). The Major depression group was defined by a CDSS score $\geq 6$.

Remission was defined by a CDSS score $<6$ under antidepressant (Guillaume Fond et al., 2018a). The unremitted group was defined by a CDSS score $\geq 6$ under antidepressant.

Other variables 
Socio-demographic information (gender, age) was reported. SZ symptomatology was assessed using the Positive And Negative Syndrome Scale (PANSS) (Kay et al., 1987). Daily global functioning was evaluated with the Global Assessment of Functioning Scale (GAF) (Startup et al., 2002). Alcohol consumption was assessed by the Alcohol Use Disorders Identification Test (AUDIT) (Saunders et al., 1993). Illness duration; tobacco consumption, drug information: antipsychotic and antidepressant treatment were also reported.

Metabolic Syndrome definition (Grundy, 2005): Sitting blood pressure (BP) and anthropometrical measurements were recorded. Two BP measurements were made 30 seconds apart in the right arm after the participant had sat and rested for at least 5 minutes. A third BP measurement was made only when the first two BP readings differed by more than $10 \mathrm{~mm} \mathrm{Hg}$. The average of the 2 closest readings was used in the analysis. Waist circumference was measured midway between the lowest rib and the iliac crest with the subjects standing. This was performed with a tape equipped with a spring-loaded mechanism to standardize tape tension during measurement. Body mass index (BMI) was calculated as weight in kilograms divided by the square of the height in meters. Overnight fasting blood was collected for metabolic profiles analysis. Fasting levels of serum triglyceride (TG) and fasting plasma glucose were measured by an automated system, and serum high-density lipoprotein cholesterol (HDL-C) level was measured by electrophoresis. Metabolic syndrome was defined according to the modified criteria of the International Diabetes Federation (IDF) (Alberti et al., 2006), which requires the presence of three or more of the following five criteria: high waist circumference (>94 cm for men and $>80 \mathrm{~cm}$ for women), hypertriglyceridemia ( $\geq 1.7 \mathrm{mM}$ or on lipid lowering medication), low HDL cholesterol level ( $<1.03 \mathrm{mM}$ in men and $<1.29 \mathrm{mM}$ in women), high blood pressure $(\geq 130 / 85 \mathrm{mmHg}$ or on antihypertensive medication), high fasting glucose concentration $(\geq 5.6 \mathrm{mM}$ or on glucoselowering medication).

Double-blinded assessment: Depression assessment and antidepressant reporting were blinded of the CRP status and blood CRP dosage was blinded of the clinical evaluation.

\subsection{Statistical analysis}

Socio-demographics, clinical characteristics, addictive behavior and treatments are presented using measures of means and dispersion (standard deviation) for continuous data and frequency distribution for categorical variables. The data was examined for normal distribution with the Shapiro-Wilk test and for homogeneity of variance with the Levene test. Comparisons between respectively MDD and non-MDD, and remitted and non-remitted individuals regarding demographic, clinical characteristics were performed using the chi-square test for categorical variables. Continuous variables were analysed with Student t-tests for normally distributed data and in case of normality violation, additional MannWhitney tests were performed to confirm the result. 
Variables with $\mathrm{P}$ values $<0.20$ in univariate analysis were included in the multivariate logistic regression model of factors associated with respectively MDD (table 1 and 3) and unremitted MDD (table 2). Tobacco smoking and metabolic syndrome were forced due to their relationship with both depression and inflammation (Fond et al., 2017a; Godin et al., 2015, 2017; Rey et al., 2017). Only total PANSS score was included in the multivariate model and not its subscores that are highly correlated. The final models included odds ratios and $95 \%$ confidence intervals. This study was a confirmatory analysis. No correction for multiple testing has therefore been carried out, which is consistent with recommendations(Bender and Lange, 2001). Analyses were conducted using SPSS 17.0 software (SPSS Inc., Chicago, IL). All statistical tests were two-tailed, with $\alpha$ level set at 0.05 .

\section{Results}

Overall, 411 patients were included (272 SZ and 139 UD) (Flow chart figure 1). 171 (41.6\%) were diagnosed with current major depression (74 (27.2\%) for SZ and 97 (69.8\%) for UD). 86 SZ (31.6\%) and 119 UD (85.6\%) were treated by antidepressant. Only 28/74 (37.8\%) of the SZ subjects with major depression were administered antidepressants vs. $87 / 97$ (89.7\%) for UD. The non-remission rate under antidepressant was 28/86=32.6\% for SZ and 87/119 (73.1\%) for UD.

Overall, $105(40.1 \%)$ of SZ and 39 (28.1\%) of UD patients were found to have abnormal CRP blood levels.

Abnormal CRP levels were found to be associated with major depression in SZ subjects independently of age, gender, psychotic symptomatology, functioning, antidepressant treatment, tobacco smoking and metabolic syndrome $(\mathrm{aOR}=1.872, \mathrm{p}=0.049)$ (Table 1). Moreover, abnormal CRP levels were also found to be associated with non-remission under antidepressant in SZ subjects independently of age, gender, psychotic symptomatology, functioning, tobacco smoking and metabolic syndrome $(\mathrm{aOR}=3.328, \mathrm{p}=0.034)$ (Table 2). No association was found between peripheral inflammation and major depression (Table 3) or remission (data not shown) in UD subjects.

\section{Discussion}

Altogether, our results may be summarized as follows: in a large sample of stabilized community-dwelling patients with severe mental disorders consulting in a daily hospital, major depression is frequent as well as non-remission under antidepressant. Abnormal CRP levels appear as a biomarker of both major depression and non-remission under antidepressant in schizophrenia but not in unipolar disorders independently of age, gender, tobacco smoking and metabolic syndrome. 
Abnormal CRP was associated with major depression. This result may yield a major finding to guide the detection and treatment of major depression in SZ subjects. We found that around $40 \%$ of SZ subjects were identified with increased CRP levels and that almost a half of those with abnormal CRP were identified with major depression (vs. $36 \%$ in those without). These rates are higher than those found in a recent national study carried out in the French Expert Center Network (Fond et al., 2016). This suggests that the rate of both depression and peripheral inflammation may vary across stabilized community-dwelling SZ patients due to multiple environmental factors including psychotropic drugs, diet, physical activity and sleep may influence both depressive symptoms and peripheral inflammation (Fond et al., 2017b; Lassale et al., 2018). This suggests that modifying these variables may decrease major depression as well as inflammation in SZ subjects. It should be underlined that our results were adjusted for smoking and metabolic syndrome, two major sources of inflammation in SZ subjects (Schürhoff et al., 2018).

Abnormal CRP levels have also been found to be associated with increased non-remission under antidepressants in schizophrenia with a stronger association than with depression. As mentioned in the rationale of the present study, antidepressants have shown anti-inflammatory properties in nonSZ subjects (Hannestad et al., 2011) but the effect of antidepressants on peripheral inflammation in SZ subjects is unclear (Faugere et al., 2018; Fond et al., 2016). The present results suggest that persistent increased CRP under antidepressant is a biomarker of non-remitted major depression in schizophrenia. This may suggest that anti-inflammatory strategies may be effective in addition or in replacement of antidepressant drugs in SZ subjects. Among those, omega 3 fatty acids and vitamin D appears as the treatments of choice that have shown anti-inflammatory and antidepressive properties in non-SZ populations (Sarris et al., 2016) as well as physical activity that has anti-inflammatory properties (Curcic et al., 2017). Other anti-inflammatory drugs including celecoxib have also shown effectiveness, however with more long-term side effects (Cho et al., 2019; Sommer et al., 2013). Nutritional interventions combined with physical activity appear as promising programs to improve depression and remission in SZ subjects with a good benefit/risk ratio.

These results have not been replicated in UD subjects, contrary to what could have been expected from previous studies (Köhler et al., 2017). These negative results may be explained by the effect of antidepressants that have shown anti-inflammatory properties in non-SZ populations (Köhler et al., 2018) but not in SZ populations (Fond et al., 2016). Most of the UD patients were treated by antidepressants, which may explain the lower rates of abnormal CRP in this population. The UD participants were fewer in number than SZ, however the high rates of major depression, antidepressant treatments, non-remission under antidepressant and abnormal CRP levels enable sufficient statistical power to explore the associations between those variables. 
In our study, the subjects with major depression were more than twice more likely to be administered antidepressants if they were diagnosed with UD than with SZ. This result may be explained by a prescription bias, as antidepressants have been suggested for long to be more effective in non-SZ subjects. However, recent data suggest that antidepressant are effect in both schizophrenic and non-schizophrenic major depression and should be equally prescribed in SZ and UD (Guillaume Fond et al., 2018a). Moreover, treating psychiatrists may be afraid of a worsening of aggressiveness under antidepressant. However, antidepressant have not been associated with increased aggressiveness in SZ patients in previous studies (G. Fond et al., 2015; Fond and Boyer, 2016). The SZ patients with major depression may be underdiagnozed due to confusion between major depression and negative symptoms (including anhedonia, blunted affect and lack of motivation). These results are consistent with those of previous studies (G. Fond et al., 2018b; Guillaume Fond et al., 2018a) and highlight the need to improve the detection of major depression in SZ subjects.

Metabolic syndrome has been found to be associated with major depression in schizophrenia independently of inflammation in our results. This result is consistent with previous findings of the FACE-SZ cohort, a national cohort of SZ patients, in which major depression was the best predictor of rapid high weight gain and metabolic syndrome at one year (Godin et al., 2017). Metabolic syndrome and depression may have a bilateral relationship by decreased physical activity and common risk factors like poor diet. Depression has been associated with several components of metabolic syndrome including carbohydrates and lipids disturbances (Suttajit and Pilakanta, 2013; Tharmaraja et al., 2019).

Limits. Psychotherapies have not been reported in the present study. However it is unlikely that psychotherapy may influence the association between peripheral inflammation and major depression. Lifestyle variables (diet, physical activity, sleep) and complementary agents intake have not been reported and may have impacted both depression and inflammation.

Strengths. The present study is the first study comparing the relationship between abnormal CRP and major depression in two severe mental disorders. The highly-sensitive CRP was used to detect low-grade peripheral inflammation (Bulzacka et al., 2016). Major depression has been evaluated for the first time with the same validated scale in the two disorders.

Conclusion

Major depression is frequent in both stabilized subjects with SZ and UD consulting in a daily hospital. UD subjects were more than twice more likely than SZ to receive antidepressants in case of major depression while antidepressants may be effective in both populations. Abnormal CRP is a proxy for peripheral inflammation and was found in the present study to be a biomarker of major depression and non-remission under antidepressant in schizophrenia. Hs-CRP dosage may therefore improve major depression diagnosis in SZ subjects and guide clinicians toward anti-inflammatory strategies to improve remission in this specific population. 
Conflicts of interest: no conflicts to disclose.

\section{References}

Addington, D., Addington, J., Maticka-Tyndale, E., 1993. Assessing depression in schizophrenia: the Calgary Depression Scale. Br. J. Psychiatry. Suppl. 39-44.

Alberti, K.G.M.M., Zimmet, P., Shaw, J., 2006. Metabolic syndrome-a new world-wide definition. A Consensus Statement from the International Diabetes Federation. Diabet. Med. 23, 469-480. https://doi.org/10.1111/j.1464-5491.2006.01858.x

Bender, R., Lange, S., 2001. Adjusting for multiple testing-when and how? J. Clin. Epidemiol. 54, 343-349. https://doi.org/10.1016/S0895-4356(00)00314-0

Bulzacka, E., Boyer, L., Schürhoff, F., Godin, O., Berna, F., Brunel, L., Andrianarisoa, M., Aouizerate, B., Capdevielle, D., Chéreau-Boudet, I., Chesnoy-Servanin, G., Danion, J.-M., Dubertret, C., Dubreucq, J., Faget, C., Gabayet, F., Le Gloahec, T., Llorca, P.-M., Mallet, J., Misdrahi, D., Rey, R., Richieri, R., Passerieux, C., Roux, P., Yazbek, H., Leboyer, M., Fond, G., FACE-SZ (FondaMental Academic Centers of Expertise for Schizophrenia) Group, 2016. Chronic Peripheral Inflammation is Associated With Cognitive Impairment in Schizophrenia: Results From the Multicentric FACE-SZ Dataset. Schizophr. Bull. 42, 1290-1302. https://doi.org/10.1093/schbul/sbw029

Cho, M., Lee, T.Y., Kwak, Y.B., Yoon, Y.B., Kim, M., Kwon, J.S., 2019. Adjunctive use of anti-inflammatory drugs for schizophrenia: A meta-analytic investigation of randomized controlled trials. Aust. N. Z. J. Psychiatry 4867419835028. https://doi.org/10.1177/0004867419835028

Curcic, D., Stojmenovic, T., Djukic-Dejanovic, S., Dikic, N., Vesic-Vukasinovic, M., Radivojevic, N., Andjelkovic, M., Borovcanin, M., Djokic, G., 2017. Positive impact of prescribed physical activity on symptoms of schizophrenia: randomized clinical trial. Psychiatr. Danub. 29, 459-465. https://doi.org/10.24869/psyd.2017.459

Faugere, M., Micoulaud-Franchi, J.-A., Faget-Agius, C., Lançon, C., Cermolacce, M., Richieri, R., 2018. High C-reactive protein levels are associated with depressive symptoms in schizophrenia. J. Affect. Disord. 225, 671-675. https://doi.org/10.1016/j.jad.2017.09.004

Felger, J.C., Haroon, E., Patel, T.A., Goldsmith, D.R., Wommack, E.C., Woolwine, B.J., Le, N.-A., Feinberg, R., Tansey, M.G., Miller, A.H., 2018. What does plasma CRP tell us about peripheral and central inflammation in depression? Mol. Psychiatry. https://doi.org/10.1038/s41380-018-0096-3

Fond, G., Berna, F., Andrianarisoa, M., Godin, O., Leboyer, M., Brunel, L., Aouizerate, B., Capdevielle, D., Chereau, I., D’Amato, T., Denizot, H., Dubertret, C., Dubreucq, J., Faget, C., Gabayet, F., Llorca, P.M., Mallet, J., Misdrahi, D., Passerieux, C., Richieri, R., Rey, R., Schandrin, A., Urbach, M., Vidailhet, P., Boyer, L., Schürhoff, F., FACE-SZ (FondaMental Academic Centers of Expertise for Schizophrenia) group, 2017a. Chronic low-grade peripheral inflammation is associated with severe nicotine dependence in schizophrenia: results from the national multicentric FACE-SZ cohort. Eur. Arch. Psychiatry Clin. Neurosci. 
https://doi.org/10.1007/s00406-017-0771-4

Fond, G., Boyer, L., 2016. Medication and aggressiveness in "real world" schizophrenia: current issues and perspectives. Psychopharmacology (Berl.) 233, 2421-2423. https://doi.org/10.1007/s00213-016-4303-0

Fond, Guillaume, Boyer, L., Berna, F., Godin, O., Bulzacka, E., Andrianarisoa, M., Brunel, L., Aouizerate, B., Capdevielle, D., Chereau, I., Coulon, N., D’Amato, T., Dubertret, C., Dubreucq, J., Faget, C., Leignier, S., Lançon, C., Mallet, J., Misdrahi, D., Passerieux, C., Rey, R., Schandrin, A., Urbach, M., Vidailhet, P., Leboyer, M., Schürhoff, F., Llorca, P.-M., FACE-SZ (FondaMental Academic Centers of Expertise for Schizophrenia) group, 2018a. Remission of depression in patients with schizophrenia and comorbid major depressive disorder: results from the FACE-SZ cohort. Br. J. Psychiatry J. Ment. Sci. 213, 464-470. https://doi.org/10.1192/bjp.2018.87

Fond, G., Boyer, L., Favez, M., Brunel, L., Aouizerate, B., Berna, F., Capdevielle, D., Chereau, I., Dorey, J.M., Dubertret, C., Dubreucq, null, Faget, C., Gabayet, F., Laouamri, H., Lancon, C., Le Strat, Y., Misdrahi, D., Rey, R., Passerieux, C., Schandrin, A., Schurhoff, F., Tronche, A.M., Urbach, M., Vidalhet, P., Llorca, P.M., Pelissolo, A., And the FACE-SZ (FondaMental Academic Centers of Expertise for Schizophrenia) group*, 2015. Medication and aggressiveness in real-world schizophrenia. Results from the FACE-SZ dataset. Psychopharmacology (Berl.). https://doi.org/10.1007/s00213-015-4167-8

Fond, Guillaume, d'Albis, M.-A., Jamain, S., Tamouza, R., Arango, C., Fleischhacker, W.W., Glenthøj, B., Leweke, M., Lewis, S., McGuire, P., Meyer-Lindenberg, A., Sommer, I.E., Winter-van Rossum, I., Kapur, S., Kahn, R.S., Rujescu, D., Leboyer, M., 2015. The promise of biological markers for treatment response in first-episode psychosis: a systematic review. Schizophr. Bull. 41, 559-573. https://doi.org/10.1093/schbul/sbv002

Fond, G., Godin, O., Boyer, L., Berna, F., Andrianarisoa, M., Coulon, N., Brunel, L., Bulzacka, E., Aouizerate, B., Capdevielle, D., Chereau, I., D’Amato, T., Dubertret, C., Dubreucq, J., Faget, C., Leignier, S., Lançon, C., Mallet, J., Misdrahi, D., Passerieux, C., Rey, R., Schandrin, A., Urbach, M., Vidailhet, P., Llorca, P.M., Schürhoff, F., Leboyer, M., FACESZ (FondaMental Academic Centers of Expertise for Schizophrenia) Group, 2018a. Chronic low-grade peripheral inflammation is associated with ultra resistant schizophrenia. Results from the FACE-SZ cohort. Eur. Arch. Psychiatry Clin. Neurosci. https://doi.org/10.1007/s00406-018-0908-0

Fond, G., Godin, O., Brunel, L., Aouizerate, B., Berna, F., Bulzacka, E., Capdevielle, D., Chereau, I., Dorey, J.M., Dubertret, C., Dubreucq, J., Faget, C., Gabayet, F., Le Strat, Y., Micoulaud-Franchi, J.A., Misdrahi, D., Rey, R., Richieri, R., Passerieux, C., Schandrin, A., Schürhoff, F., Tronche, A.M., Urbach, M., Vidalhet, P., Llorca, P.M., Leboyer, M., FACE-SZ (FondaMental Academic Centers of Expertise for Schizophrenia) group, 2016. Peripheral subinflammation is associated with antidepressant consumption in schizophrenia. Results from the multi-center FACE-SZ data set. J. Affect. Disord. 191, 209-215. https://doi.org/10.1016/j.jad.2015.11.017

Fond, Guillaume, Lançon, C., Auquier, P., Boyer, L., 2018b. C-Reactive Protein as a Peripheral Biomarker in Schizophrenia. An Updated Systematic Review. Front. Psychiatry 9, 392. https://doi.org/10.3389/fpsyt.2018.00392 
Fond, G., Resseguier, N., Schürhoff, F., Godin, O., Andrianarisoa, M., Brunel, L., Bulzacka, E., Aouizerate, B., Berna, F., Capdevielle, D., Chereau, I., D’Amato, T., Dubertret, C., Dubreucq, J., Faget, C., Gabayet, F., Lançon, C., Llorca, P.M., Mallet, J., Misdrahi, D., Passerieux, C., Rey, R., Schandrin, A., Urbach, M., Vidailhet, P., Boyer, L., Leboyer, M., FACE-SZ (FondaMental Academic Centers of Expertise for Schizophrenia) group, 2017b. Relationships between low-grade peripheral inflammation and psychotropic drugs in schizophrenia: results from the national FACE-SZ cohort. Eur. Arch. Psychiatry Clin. Neurosci. https://doi.org/10.1007/s00406-017-0847-1

Fond, G., Tinland, A., Boucekine, M., Girard, V., Loubière, S., Auquier, P., Boyer, L., French Housing First Study Group, 2018b. Prescription of potentially inappropriate psychotropic drugs in homeless people with schizophrenia and bipolar disorders. Results from the French Housing First (FHF) program. Prog. Neuropsychopharmacol. Biol. Psychiatry. https://doi.org/10.1016/j.pnpbp.2018.08.024

Godin, O., Leboyer, M., Gaman, A., Aouizerate, B., Berna, F., Brunel, L., Capdevielle, D., Chereau, I., Dorey, J.M., Dubertret, C., Dubreucq, J., Faget, C., Gabayet, F., Le Strat, Y., Llorca, P.M., Misdrahi, D., Rey, R., Richieri, R., Passerieux, C., Schandrin, A., Schürhoff, F., Urbach, M., Vidalhet, P., Girerd, N., Fond, G., FACE-SZ group, 2015. Metabolic syndrome, abdominal obesity and hyperuricemia in schizophrenia: Results from the FACE-SZ cohort. Schizophr. Res. https://doi.org/10.1016/j.schres.2015.07.047

Godin, O., Leboyer, M., Schürhoff, F., Boyer, L., Andrianarisoa, M., Brunel, L., Bulzacka, E., Aouizerate, B., Berna, F., Capdevielle, D., D’Amato, T., Denizot, H., Dubertret, C., Dubreucq, J., Faget, C., Gabayet, F., Llorca, P.M., Mallet, J., Misdrahi, D., Passerieux, C., Rey, R., Richieri, R., Schandrin, A., Urbach, M., Vidailhet, P., Costagliola, D., Fond, G., FACE-SZ (FondaMental Academic Centers of Expertise for Schizophrenia) group, 2017. Predictors of rapid high weight gain in schizophrenia: Longitudinal analysis of the French FACE-SZ cohort. J. Psychiatr. Res. 94, 62-69. https://doi.org/10.1016/j.jpsychires.2017.06.008

Grundy, S.M., 2005. Diagnosis and Management of the Metabolic Syndrome: An American Heart Association/National Heart, Lung, and Blood Institute Scientific Statement. Circulation 112, 2735-2752. https://doi.org/10.1161/CIRCULATIONAHA.105.169404

Hannestad, J., DellaGioia, N., Bloch, M., 2011. The effect of antidepressant medication treatment on serum levels of inflammatory cytokines: a meta-analysis. Neuropsychopharmacology 36, 2452-2459.

Kay, S.R., Fiszbein, A., Opler, L.A., 1987. The positive and negative syndrome scale (PANSS) for schizophrenia. Schizophr. Bull. 13, 261-276.

Köhler, C.A., Freitas, T.H., Maes, M., de Andrade, N.Q., Liu, C.S., Fernandes, B.S., Stubbs, B., Solmi, M., Veronese, N., Herrmann, N., Raison, C.L., Miller, B.J., Lanctôt, K.L., Carvalho, A.F., 2017. Peripheral cytokine and chemokine alterations in depression: a metaanalysis of 82 studies. Acta Psychiatr. Scand. 135, 373-387.

https://doi.org/10.1111/acps.12698

Köhler, C.A., Freitas, T.H., Stubbs, B., Maes, M., Solmi, M., Veronese, N., de Andrade, N.Q., Morris, G., Fernandes, B.S., Brunoni, A.R., Herrmann, N., Raison, C.L., Miller, B.J., Lanctôt, 
K.L., Carvalho, A.F., 2018. Peripheral Alterations in Cytokine and Chemokine Levels After Antidepressant Drug Treatment for Major Depressive Disorder: Systematic Review and MetaAnalysis. Mol. Neurobiol. 55, 4195-4206. https://doi.org/10.1007/s12035-017-0632-1

Lassale, C., Batty, G.D., Baghdadli, A., Jacka, F., Sánchez-Villegas, A., Kivimäki, M., Akbaraly, T., 2018. Healthy dietary indices and risk of depressive outcomes: a systematic review and meta-analysis of observational studies. Mol. Psychiatry.

https://doi.org/10.1038/s41380-018-0237-8

Micoulaud-Franchi, J.-A., Faugere, M., Weibel, S., Faget, C., Lancon, C., Richieri, R., Cermolacce, M., 2018. Toward a transdiagnostic tool to evaluate depressive symptoms across mental disorders: Validation of the Calgary depression rating scale in patients with major depressive disorder. Psychiatry Res. 268, 68-71.

https://doi.org/10.1016/j.psychres.2018.06.062

Rey, R., D’Amato, T., Boyer, L., Brunel, L., Aouizerate, B., Berna, F., Capdevielle, D., Chereau, I., Chesnoy-Servanin, G., Denizot, H., Dorey, J.-M., Dubertret, C., Dubreucq, J., Faget, C., Gabayet, F., Lancon, C., Mallet, J., Misdrahi, D., Passerieux, C., Schandrin, A., Schürhoff, F., Urbach, M., Vidailhet, P., Llorca, P.-M., Fond, G., FACE-SZ (FondaMental Academic Centers of Expertise for Schizophrenia) group, 2017. Nicotine dependence is associated with depression and childhood trauma in smokers with schizophrenia: results from the FACE-SZ dataset. Eur. Arch. Psychiatry Clin. Neurosci. https://doi.org/10.1007/s00406017-0779-9

Sarris, J., Murphy, J., Mischoulon, D., Papakostas, G.I., Fava, M., Berk, M., Ng, C.H., 2016. Adjunctive Nutraceuticals for Depression: A Systematic Review and Meta-Analyses. Am. J. Psychiatry 173, 575-587. https://doi.org/10.1176/appi.ajp.2016.15091228

Saunders, J.B., Aasland, O.G., Babor, T.F., de la Fuente, J.R., Grant, M., 1993. Development of the Alcohol Use Disorders Identification Test (AUDIT): WHO Collaborative Project on Early Detection of Persons with Harmful Alcohol Consumption--II. Addict. Abingdon Engl. 88, 791-804.

Schürhoff, F., Fond, G., Berna, F., Bulzacka, E., Godin, O., Boyer, L., Misdrahi, D., Andrianarisoa, M., Brunel, L., Coulon, N., Aouizerate, B., Capdevielle, D., Chereau, I., D’Amato, T., Dubertret, C., Dubreucq, J., Faget, C., Gabayet, F., Mallet, J., Rey, R., Lancon, C., Passerieux, C., Schandrin, A., Urbach, M., Vidailhet, P., Leboyer, M., Llorca, P.M., FACE-SZ (FondaMental Academic Centers of Expertise for Schizophrenia) group, 2018. [The 10-year findings from the FondaMental Academic Center of Expertise for Schizophrenia (FACE-SZ): Review and recommendations for clinical practice]. L'Encephale. https://doi.org/10.1016/j.encep.2018.07.007

Sommer, I.E., Westrhenen, R. van, Begemann, M.J.H., Witte, L.D. de, Leucht, S., Kahn, R.S., 2013. Efficacy of Anti-inflammatory Agents to Improve Symptoms in Patients With Schizophrenia: An Update. Schizophr. Bull. sbt139. https://doi.org/10.1093/schbul/sbt139

Startup, M., Jackson, M.C., Bendix, S., 2002. The concurrent validity of the Global Assessment of Functioning (GAF). Br. J. Clin. Psychol. 41, 417-422.

Suttajit, S., Pilakanta, S., 2013. Prevalence of metabolic syndrome and its association with depression in patients with schizophrenia. Neuropsychiatr. Dis. Treat. 9, 941-946. 
1 https://doi.org/10.2147/NDT.S47450

2 Tharmaraja, T., Stahl, D., Hopkins, C.W.P., Persaud, S.J., Jones, P.M., Ismail, K., Moulton, 3 C.D., 2019. The Association Between Selective Serotonin Reuptake Inhibitors and Glycemia: 4 A Systematic Review and Meta-Analysis of Randomized Controlled Trials. Psychosom. Med. 5 81, 570-583. https://doi.org/10.1097/PSY.0000000000000707

6 Wysokiński, A., Margulska, A., Strzelecki, D., Kłoszewska, I., 2014. Levels of C-reactive 7 protein (CRP) in patients with schizophrenia, unipolar depression and bipolar disorder. Nord.

8 J. Psychiatry 1-8. https://doi.org/10.3109/08039488.2014.984755

9 
